\title{
Outlook and overview of microplastics pollution in ecological environment
}

\author{
Zhao Bin ${ }^{1}$, Cheng Yongqiang ${ }^{1}$, Guo Cuilian ${ }^{1}$, Liu Maoke ${ }^{1}$, Yao Puyu ${ }^{1}$, and Zhou Yang ${ }^{1, *}$ \\ ${ }^{1}$ Institute of Oceanographic Instrumentation, Qilu University of Technology (Shandong Academy of Sciences); Shandong Key \\ Laboratory of Ocean Environmental Monitoring Technology, Qingdao City, Shandong Province, 266001, China
}

\begin{abstract}
Microplastics are attracting more and more attention as a new type of pollutant in the ecological environment. Microplastics are difficult to degrade because of their unique physical and chemical properties. Some microplastics adsorbed toxic chemicals (e.g. heavy metals or organic pollutants) will cause a series of toxicological effects in organisms. This paper summarized the research progress in microplastics from the aspects of the types, distribution, detection and the toxicological effects. In addition, future research directions were also proposed and discussed.
\end{abstract}

\section{Introduction}

In recent years, the pollution of plastic particles has attracted much attention[1,2]. Due to the extensive use of plastic products, the waste and residues inevitably enter the water environment and the plastic particles are difficult to degrade in the environment due to their unique physical and chemical properties[3]. The sources of microplastics mainly include primary microplastics directly discarded into the environment and secondary microplastics formed by the fracture and decomposition of large pieces of plastic[4-6]. Primary microplastics are small plastic particles with micron or nanometer sized particles, such as detergent, personal skin care products, and industrial raw materials. Secondary microplastics are those that broken up into plastic particles or fragments from larger plastic wastes in the environment. These microplastics migrate among the atmosphere, water (fresh water and sea), soil and creatures, and then cause harm to the ecological environment.

\section{Types and distribution of microplastics}

In 2004, Thompson et al. [17]firstly used the term "microplastics" to describe the tiny plastic particles observed under a microscope. In generally, plastics with a diameter of less than $5 \mathrm{~mm}$ in the environment are called microplastics. The size of microplastics affects the properties of the particles, and the little size also increases the difficulty of separating and detecting the plastic particles. It's usually classified by the size of plastic particles. Georg et al. [18]divided the microplastics into two levels of $20 \mu \mathrm{m}-1 \mathrm{~mm}$ and $1 \mathrm{~mm}$ $-5 \mathrm{~mm}$. Hidalgo et al. [19] classified the microplastics into two levels of $1 \mu \mathrm{m}-500 \mu \mathrm{m}$ and $500 \mu \mathrm{m}-5 \mathrm{~mm}$. Plastic particles less than $100 \mathrm{~nm}$ are usually called plastic
The hazards associated with microplastics mainly include three aspects. First, lots of microplastics can easily clog the feeding organs of animals. At present, many dead marine organisms including zooplankton, benthic invertebrates, bivalves, fish, seabirds and large marine mammals, have been reported due to feeding on microplastics [7, 8]. Second, many microplastics contain poisons that can be released when they enter the ecological environment $[9,10]$. Third, the microplastics can easily adsorb toxic chemicals (e.g. heavy metals or organic pollutants) due to their large surface area and hydrophobic properties[11-15]. The microplastics carried toxic chemicals will cause the toxic effects in organisms. In recent years, the synergistic effects of microplastics and the pollutants on organisms have been widely recognized[16]. The European Union and the United States have put microplastics pollution into national and international marine conservation policies and legislation (such as the European Union's ocean strategy framework and the National Oceanic and Atmospheric Administration).

nanoparticles. There are many types of microplastics in terms of materials, mainly including polyethylene (PE), polyvinyl chloride (PVC), polypropylene (PP), polyurethane (PUR), polyethylene terephthalate (PET) and polystyrene (PS) [20]. In terms of the shape of plastic particles, there are spherical, fibrous, fragmentary and irregular forms[21].

Plastic debris in the environment can be transported by wind, rivers, ocean currents and other external forces. Microplastics can reach the remote corners of the earth, ranging from the mountains to the bottom of the sea. Microplastics are globally distributed and have been found in the fresh water, land, estuaries, ocean, deep sea and polar regions. Microplastics exist in everywhere and they are difficult to completely degrade in the natural environment [22]. Therefore, it is important to decrease

\footnotetext{
* Corresponding author: zhouyang112sd $@ 163 . c o m$
} 
microplastics pollution for protecting ecological environmental safety and human health.

\section{Detection of microplastics}

To protect ecological environment from microplastics pollution, it is necessary and imperative to establish accurate and efficient methods to detect the microplastics in the environment. The process of detecting the microplastics involves sample collection, pretreatment and qualitative or quantitative analysis[23].

There are mainly three methods to collect microplastics including selective sampling, bulk sampling and volume-reduced sampling[19]. Selective sampling is directly picking microplastics in environmental samples by visual identification, which is suitable to easily recognizable microplastics with the size above $1 \mathrm{~mm}$. Bulk sampling is getting the entire volume of the sample without reducing it during the sampling process. This method is most appropriate when microplastics cannot be easily identified visually. Volume-reduced sampling refers to the method that many samples are extracted immediately at the sampling site, such as filtration and screening, and the target components are retained for further analysis. Selective sampling is usually limited to some extent when the microplastics are little and difficult observation. Therefore, bulk sampling and volume-reduced sampling are the optimized method. Pretreatment is also the key process to separate and identify microplastic components from samples. At present, the common pretreatment methods mainly include density separation, filtration and screening by visual inspection[24-27].

Microplastics are different in shape, color and composition. Therefore, it is difficult to quantitatively analyze the microplastics. Physical morphology characterization and chemical component identification analysis are common methods. Physical morphology characterization is mainly based on high resolution microscope (e.g. scanning electron microscope)[20, 28, 29]. Chemical component identification is usually carried out with the aid of chemical analytical instruments, such as Raman Spectroscopy, Fourier Transform Infrared Spectroscopy and Gas Chromatograph-Mass Spectrometry[30-32].

\section{Toxicological effects of microplastics}

Microplastics have a small size and are easy to be mistakenly eaten by planktonic or filter feeders. It is possible for microplastics to enter the body if people eat these organisms $[33,34]$. Therefore, it is very necessary to study the toxicological effects of microplastics. The toxicological effects of microplastics are mainly reflected in the microplastics themselves, the chemical substances released by microplastics and the toxic pollutants adsorbed by microplastics[35].

Microplastics ingested by organisms will also release carried pollutants and their own plastic additives, which would cause the changes in molecular biology, histology, cytology and ethology[36, 37]. Now, the study of toxicological effects of microplastics is chiefly focus on marine creatures. Plasticizers in the microplastics can affect animal reproduction and induce genetic aberrations. Rochman et al.[38] reported that the toxic chemicals carried by microplastics can stress fish livers, and further demonstrated that microplastics and the enriched organic pollutants can affect marine creatures on a genetic level. Avio et al.[39] assessed the toxicological risks of microplastics in marine shellfish. Microplastics were deposited mainly in the hemolymphs and digestive organs of marine shellfish, which could cause the changes of immunological reactions, lysosome-associated compartment, antioxidant system, neurotoxic reactions and genotoxic reactions.

\section{Conclusion}

As a new type of pollutants in recent years, microplastics in the environment have a complex relationship with people's life and health[40]. Meanwhile, the microplastics pollution is a long-term process, which requires researchers to carry out systematic and in-depth study. Although the extensive research on the separation, identification and the toxicity of microplastics have been done, there are still many problems to be solved.

According to the current research progress, the future research will focus on the following aspects. First, it is necessary and imperative to establish accurate and efficient microplastics analysis method. At present, the sampling and analysis methods are not uniform, which is one of the main problems during the research of the migration, transformation and distribution of microplastics. To compare and analyze the research data from different sources, the standardization of sampling and identification method should be further developed. In addition to the standardization methods, on-site analytical sensors for microplastics will also be the focus of future research and development. Second, the influence of dynamic environment on the migration and distribution of microplastics should be further developed. Numerous reports suggest that the deep sea is the final collection place of microplastics, so the marine dynamic process will directly affect the migration and sedimentation of microplastics. Therefore, the research of microplastics should be combined with the dynamic environment to better their monitor of migration and distribution behaviors. Third, compound toxicity effects of microplastics should be further investigated. At present, researches on toxicological effects of microplastics are mainly focused on laboratory simulation, which could not well interpret the interaction between microplastics and pollutants in a real environment. The understanding of the possible toxicological effects of microplastics needs to be further improved.

\section{Acknowledgment}

Financial supports from Natural Science Foundation of China (No. 21207080), Natural Science Foundation of Shandong Province (No. ZR2011BQ021), Outstanding youth training 
program of Shandong academy of sciences (No. YJQ303), National Key Technology R\&D Program of the Ministry of Science and Technology (2012BAF14B04) are gratefully acknowledged.

\section{References}

1. Sul JA, Costa MF. Environmental Pollution 185, 352 (2014)

2. Chen A. Science 8 (2015)

3. Rochman CM, Browne MA, Halpern BS, Hentschel BT, Hoh E, Karapanagioti HK, Rios-Mendoza LM, Takada H, Teh S, Thompson RC. Nature 494, 169 (2013)

4. Fendall LS, Sewell MA. 58, 1225 (2009)

5. Mark Anthony B, Phillip C, Niven SJ, Emma T, Andrew T, Tamara G, Richard T. Environmental Science \& Technology 45, 9175 (2011)

6. Eriksen M, Lebreton LCM, Carson HS, Thiel M, Moore CJ, Borerro JC, Galgani F, Ryan PG, Reisser J. PLOS ONE 9, e111913 (2014)

7. Derraik JGB. Marine Pollution Bulletin 44, 842-852 (2002)

8. Thompson RC. Microplastics in the Marine Environment: Sources, Consequences and Solutions (2015)

9. Jrg O, Ulrike SO, Werner K, Oana J, Ilka L, Kusk KO, Leah W, Santos EM, Paull GC, Look KJW, Van. Philosophical Transactions of the Royal Society of London 364, 2047 (2009)

10. Meeker JD, Sheela S, Swan SH. Philosophical Transactions of the Royal Society of London 364, 2097 (2009)

11. Frias J, Sobral P, Ferreira AM. Marine Pollution Bulletin 60, 1988 (2010)

12. Hirai $H$, Takada $H$, Ogata $Y$, Yamashita R, Mizukawa K, Saha M, Kwan C, Moore C, Gray H, Laursen D. Marine Pollution Bulletin 62, 1683 (2011)

13. Van A, Rochman CM, Flores EM, Hill KL, Vargas E, Vargas SA, Hoh E. Chemosphere 86, 258 (2012)

14. Holmes LA, Andrew T, Thompson RC. Environmental Pollution 160, 42 (2012)

15. Rochman CM, Hentschel BT, Teh SJ. Plos One 9, e85433 (2014)

16. Zettler ER, Mincer TJ, Amaral-Zettler LA. Environmental Science \& Technology 47, 7137 (2013)

17. Thompson RC, Ylva O, Mitchell RP, Anthony D, Rowland SJ, John AWG, Daniel MG, Russell AE. Science 304, 838-838 (2004)

18. H G, G F, W S. Guidance on Monitoring of Marine Litter in European Seas(2013)

19. Hidalgo-Ruz V, Gutow L, Thompson RC, Thiel M. Environmental Science \& Technology 46, 3060 (2012)

20. Vianello A, Boldrin A, Guerriero P, Moschino V, Rella R, Sturaro A, Ros LD. Estuarine Coastal \& Shelf Science 130, 54 (2013)

21. Zhenzhong L, Liping L, Weijie H, Zhanli C. Environmental Science \& Technology 42, 231 (2019)
22. Andrés C, Fidel E, J Ignacio GG, Xabier I, Bárbara U, Santiago HL, Palma AT, Sandra N, Juan GDL, Andrea R. Proc Natl Acad Sci USA 111, 10239 (2014)

23. Kun W, Kunde L, Dongxing Y. Environmental Chemistry 36, 27 (2017)

24. Zhao S, Zhu L, Wang T, Li D. Marine Pollution Bulletin 86, 562 (2014)

25. Desforges JPW, Galbraith M, Dangerfield N, Ross PS. Marine Pollution Bulletin 79, 94 (2014)

26. Desforges JPW, Galbraith M, Ross PS. Archives of Environmental Contamination \& Toxicology 69, 320 (2015)

27. Lusher AL, Hernandez-Milian G, O'Brien J, Berrow S, O'Connor I, Officer R. Environmental Pollution 199, 185 (2015)

28. Cauwenberghe LV, Vanreusel A, Mees J, Janssen CR. Environmental Pollution 182, 495 (2013)

29. Fries E, Dekiff JH, Willmeyer J, Nuelle MT, Ebert M, Remy D. Environmental Science Processes \& Impacts 15, 1949 (2013)

30. Fischer D. Agu Fall Meeting (2016)

31. Löder M, Gerdts G. Applied Mechanics \& Materials 405-408, 2644 (2014)

32. Käppler A, Fischer M, Scholz-Böttcher BM, Oberbeckmann S, Labrenz M, Fischer D, Eichhorn KJ, Voit B. Analytical \& Bioanalytical Chemistry 410, 5313 (2018)

33. Li J, Yang D, Li L, Jabeen K, Shi H. Environmental Pollution 207, 190 (2015)

34. Cauwenberghe LV, Janssen CR. Environmental Pollution 193, 65 (2014)

35. Wright SL, Kelly FJ. Environmental Science \& Technology 51, 6634 (2017)

36. Zhao S, Ward JE, Danley M, Mincer TJ. Environmental Science \& Technology 52, 11038 (2018)

37. Cole, Matthew. University of Exeter 47, 12 (2014)

38. Rochman CM, Hoh E, Kurobe T, Teh SJ. Sci Rep 3, 3263 (2013)

39. Avio CG, Gorbi S, Milan M, Benedetti M, Fattorini D, D'Errico G, Pauletto M, Bargelloni L, Regoli F. Environmental Pollution 198, 211 (2015)

40. Barboza LGA, Vethaak AD, Lavorante BRBO, Lundebye AK, Guilhermino L. Marine Pollution Bulletin 133, 336 (2018) 